\title{
Detection of Potentially Toxic Metals by SERS using Salen Complexes
}

\author{
Julie Docherty, ${ }^{a}$ Samuel Mabbott, ${ }^{a}$ Ewen Smith, ${ }^{a}$ Karen Faulds, ${ }^{a}$ Christine Davidson, ${ }^{b}$ John Reglinski ${ }^{b}$ \\ and Duncan Graham*a
}

Received (in XXX, XXX) Xth XXXXXXXXX 20XX, Accepted Xth XXXXXXXXX 20XX

${ }_{5}$ DOI: $10.1039 / \mathbf{b 0 0 0 0 0 0 x}$

Surfaced enhanced Raman scattering (SERS) can discriminate between metal complexes due to the characteristic "spectral fingerprints" obtained. As a result, SERS has the potential to develop relatively simple and sensitive methods of detecting and quantifying a range of metal ions in solution. This could be beneficial for the environmental monitoring of potentially toxic metals (PTMs). Here, salen was used as a

10 ligand to form complexes of $\mathrm{Ni}(\mathrm{II}), \mathrm{Cu}(\mathrm{II}), \mathrm{Mn}$ (II) and $\mathrm{Co}(\mathrm{II})$ in solution. The SERS spectra showed characteristic spectral differences specific to each metal complex, thus allowing the identification of each of these metal ions. This method allows a number of metal ions to be detected using the same ligand and an identical preparation procedure. The limit of detection (LOD) was determined for each metal ion, and it was found that $\mathrm{Ni}(\mathrm{II}), \mathrm{Cu}(\mathrm{II})$ and $\mathrm{Mn}(\mathrm{II})$ could be detected below the WHO's recommended limits in

15 drinking water at 1,2 and $2 \mu \mathrm{g} \mathrm{L}{ }^{-1}$, respectively. Co(II) was found to have an LOD of $20 \mu \mathrm{g} \mathrm{L} \mathrm{L}^{-1}$, however no limit has been set for this ion by the WHO as the concentration of $\mathrm{Co}(\mathrm{II})$ in drinking water is generally $<1-2 \mu \mathrm{g} \mathrm{L}^{-1}$. A contaminated water sample was also analysed where $\mathrm{Mn}(\mathrm{II})$ was detected at a level of 800 $\mu \mathrm{g} \mathrm{L}^{-1}$.

\section{Introduction}

${ }_{20}$ Schiff bases were discovered in 1864 by Hugo Schiff and are derived from the condensation between a carbonyl compound and a primary amine. ${ }^{1}$ Schiff bases to coordinate to a range of metal ions via the imine nitrogen and at least one other group, usually linked to the carbonyl compound. ${ }^{2}$ They are versatile and are used 25 in a wide variety of applications. ${ }^{3}$ For example, aromatic Schiff bases or their metal complexes catalyse a range of reactions and their pharmacological properties have also been widely studied, including their antiviral, antibacterial and antifungal activity. ${ }^{4-10}$

As Schiff bases are good chelating agents, they can also be used 30 detect potentially toxic metals (PTMs). The hazardous and toxic effects that PTMs have on the environment and human health means that monitoring is essential to that the levels present in the environment do not exceed the recommended limits as set out by environmental bodies such as the World Health Organisation 35 (WHO). Methods of PTM quantitation usually use techniques such as ICP-MS/ICP-AES, which are commonly laboratory-based instrumentation and can have high implementation and running costs. As a result, they may not be accessible to all analytical groups, especially those in developing countries and therefore new, ${ }_{40}$ simpler, low-cost and potentially portable techniques are required.

Methods using UV-vis spectroscopy and fluorescence to detect metal complexes can potentially overcome these issues. As Schiff bases tend to be coloured, they can undergo a colour change on complexing to metal ions enabling detection of the change by UV45 vis spectrometers. ${ }^{11,} 12$ Schiff base derivatives have also been exploited for the recognition of metal ions using fluorescence detection. ${ }^{13-15}$ Recently however, these two techniques have also been combined to provide a single sensor for the detection of multiple metal ions. For example, Tang et al. have used a 50 rhodamine B hydrazide methyl-5-formyl-1H-pyrrole-2carboxylate Schiff base that is capable of detecting both $\mathrm{Cu}$ (II) and $\mathrm{Hg}$ (II) ions, the former colourimetrically and the latter fluorescently. ${ }^{16}$ In the presence of $\mathrm{Cu}$ (II), the colourless Schiff base changed to pink, accompanied by a new strong absorption band 55 centred at $556 \mathrm{~nm}$. $\mathrm{Hg}$ (II) was the only ion amongst 16 tested that showed a fluorescence enhancement. Choi et al. have synthesised a Schiff base from 8-hydroxyjulolidine-9-carboxyaldehyde and 1(3-aminopropyl) imidazole which can colourimetrically detect $\mathrm{Fe}$ (II) and $\mathrm{Fe}$ (III), while also sensing $\mathrm{Zn}$ (II) and $\mathrm{Al}(\mathrm{III})$ 60 fluorescently. ${ }^{17}$ The Schiff base changed from colourless to orange upon coordination with $\mathrm{Fe}(\mathrm{II})$, and to purple with $\mathrm{Fe}(\mathrm{III})$. Meanwhile, $\mathrm{Zn}$ (II) was the only metal ion (amongst 17 tested) that increased the emission intensity of the Schiff base in a mixture of water and acetonitrile. When the solvent was changed to DMF, ${ }_{65} \mathrm{Al}(\mathrm{III})$ was the only metal ion to enhance the emission signal. These examples demonstrate the potential of UV-vis and fluorescence to detect metal ions using Schiff bases.

Although colourimetric and fluorometric methods are useful for the determination of metal ions, the drawbacks of these techniques 70 include a lack of selectivity/sensitivity and are liable to interference from other metal ions. However, the main disadvantage is the limited ability to multiplex due to the broad, overlapping signals obtained from these methods. This issue can potentially be overcome by using surface enhanced Raman 75 scattering (SERS) which can give molecularly specific data due to the sharp signals produced. This enables a range of metal ions to 
be identified in situ in solution from complexes formed with a single ligand. In addition, the development of methods using SERS detection which have the potential for environmental monitoring is timely because of the recent development of handheld detectors 5 and the lower costs of some of these units.

This has been demonstrated by Kim et. al. who have used cyanide for the detection of $\mathrm{Cr}$ (III), $\mathrm{Fe}(\mathrm{III}), \mathrm{Fe}(\mathrm{II}), \mathrm{Ni}(\mathrm{II})$ and $\mathrm{Mn}$ (II) in solution. ${ }^{18}$ The shift in the $\mathrm{CN}$ stretch on complexing was monitored using SERS. In the presence of trivalent ions, this band 10 blue-shifted by up to $64 \mathrm{~cm}^{-1}$, whereas for divalent metal ions, it was blue-shifted by $26-35 \mathrm{~cm}^{-1}$. A low detection limit of $1 \mathrm{fM}$ was reported making this method potentially useful for the detection of metal ions in environmental samples. Tsoutsi et. al. have reported the use of terpyridine for the simultaneous detection of $\mathrm{Cu}(\mathrm{II})$ and ${ }_{15} \mathrm{Co}$ (II) at ultratrace levels. ${ }^{19}$ The terpyridine was attached to silver nanoparticles and used as a SERS substrate via the dithiocarbamate unit. Complexation with either $\mathrm{Co}(\mathrm{II})$ or $\mathrm{Cu}(\mathrm{II})$ produced changes in the vibrational SERS spectra of the terpyridine. We have previously used 2,2'-bipyridyl (bipy) to detect six different metal 20 ions. ${ }^{20}$ Each metal ion uniquely alters the SERS spectrum of the bipy ligand upon coordination, and these changes can be used to identify which metal ion is present. It was shown that $\mathrm{Zn}(\mathrm{II})$ and $\mathrm{Cu}$ (II) could be detected below the WHO's recommended limits of 0.22 and $0.6 \mathrm{mg} \mathrm{L}^{-1}$, respectively. ${ }^{21}$

25 In this work, a $[\mathrm{O}, \mathrm{N}, \mathrm{N}, \mathrm{O}]$ tetradentate bis-Schiff base ligand was synthesised by reacting salicylaldehyde with 1,2diaminoethane. This ligand (salen) was used to coordinate to $\mathrm{Ni}(\mathrm{II}), \mathrm{Co}(\mathrm{II}), \mathrm{Cu}(\mathrm{II})$ and $\mathrm{Mn}(\mathrm{II})$, and Figure 1 shows the binding of metal ions to salen. It was found that the SERS spectra of each 30 metal-salen complex was significantly different enabling the unique spectra to be used to identify which metal ion was present. Detection limits were also calculated and to demonstrate the potential utility of the approach, a sample of contaminated water was analysed.

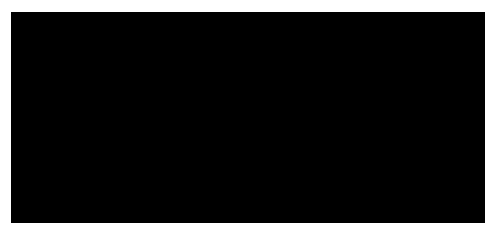

Figure 1: Diagram representing the coordination of metal ions to salen

\section{Experimental}

\section{Chemicals}

All reagents were purchased from Sigma-Aldrich and used as received. Freshwater samples were obtained from Loch Thom, ${ }_{45}$ Greenock, UK and contaminated water from Gourock burn, UK.

\section{Nanoparticle Synthesis}

Silver citrate nanoparticles were prepared by following a modified version of the Lee and Meisel method. ${ }^{22}$ Briefly, $90 \mathrm{mg}$ of silver 50 nitrate was added to $500 \mathrm{~mL}$ water and heated to boiling under vigorous stirring. A $1 \%$ aqueous solution of sodium citrate was added $(10 \mathrm{~mL})$ and heating was continued for a further $20 \mathrm{~min}$. The solution was then left to cool to room temperature. In order to assess the quality of the colloid produced, a UV-vis spectrum of ${ }_{55}$ the colloid was obtained. Ideally, colloid made in this way should have a $\lambda_{\max }$ of approximately $400 \mathrm{~nm}$ and a full width at half maximum (FWHM) of less than $100 \mathrm{~nm}$ in order to be as close to monodispersity as possible. The colloid used throughout this work had a $\lambda_{\max }$ of $401 \mathrm{~nm}$ and a FWHM of around $90 \mathrm{~nm}$.

60

\section{Sample Preparation}

A $5 \mathrm{mM}$ stock solution of salen $\left(\mathrm{C}_{16} \mathrm{H}_{16} \mathrm{~N}_{2} \mathrm{O}_{2}\right)$ was prepared by dissolving $6.7 \mathrm{mg}$ in $5 \mathrm{~mL}$ of acetone, which was subsequently diluted to $100 \mu \mathrm{M}$. Metal salt solutions were prepared by ${ }_{65}$ dissolving the appropriate amount in distilled water to give the desired concentration.

$25 \mu \mathrm{L}$ of each metal ion solution was added to $25 \mu \mathrm{L}$ salen (100 $\mu \mathrm{M})$, which was then left overnight to allow complexation. The complexes can be left for a shorter period of time however, they 70 were left overnight to ensure complete coordination of the metal ions to the ligand. AgNPs $(200 \mu \mathrm{L})$ were then added to the salenmetal complexes and aggregation was induced by the addition of $10 \mu \mathrm{L} 0.1 \mathrm{M} \mathrm{MgBr}$ salt. Three replicates of each standard was prepared and analysed using SERS.

75 Freshwater obtained from Loch Thom was spiked with varying concentrations of metal ions and analysed using SERS within a couple of days of collection. Environmental samples, such as the freshwater collected for this work, is usually preserved in $2 \%$ nitric acid in order to keep the metal ions in solution. However, as this 80 induces aggregation when added to the AgNPs, the samples had to be analysed as soon as possible. An aliquot for ICP-MS analysis was however preserved in nitric acid. Contaminated water from Gourock burn was not spiked and analysed as collected.

\section{${ }_{85}$ Instrumentation}

Rapid SERS analysis was conducted using an Avalon Instruments Ltd. RamanStation compact benchtop spectrometer (PerkinElmer, Waltham, MA). The system uses a $532 \mathrm{~nm}$ diode laser with a laser power of $100 \mathrm{~mW}$. All measurements were 90 carried out using a $10 \mathrm{~s}$ exposure time and a resolution of $0.5 \mathrm{~cm}^{-1}$ in the range $250-2000 \mathrm{~cm}^{-1}$. The instrument is fitted with a motorised $x-y-z$ sample stage which accepts 96-well microtitre plates and the instrument's software was used to automatically drive the stage to each well in turn. The instrument was calibrated 95 using an ethanol standard to ensure optimum distance between the sample and the laser aperture.

When analysing environmental samples, a portable Snowy SnRI instrument was used, which has a $532 \mathrm{~nm}$ diode laser with a power of $50 \mathrm{~mW}$ (SnRI, Wyoming, USA). All measurements were 100 obtained using a sample volume of $500 \mu \mathrm{L}$ and a 10 s exposure time.

ICP-MS analysis of the freshwater samples was conducted on an Agilent 7700 instrument (Agilent Technologies, Santa Clara, USA).

105

\section{Results \& Discussion}

\section{Concentration Study}


In order to determine a suitable concentration of salen required to give optimal results, a study was conducted by comparing the SERS spectra of different concentrations of salen with no metal ions present, to those obtained when $1 \mu \mathrm{M} \mathrm{Ni}$ (II) was added. The ${ }_{5}$ SERS spectra from the uncomplexed salen gives a weak SERS response from the ligand however, upon addition of $\mathrm{Ni}$ (II), strong SERS signals are produced. This is shown in the SI which compares the SERS response of the free ligand to that of the Nisalen complex. The results from adding $1 \mu \mathrm{M} \mathrm{Ni(II)} \mathrm{to} \mathrm{varying}$ 10 concentrations of salen are shown in Figure 2. It can be seen that the SERS signal increases in intensity as the concentration is increased up to $10 \mu \mathrm{M}$ salen, at which point the intensity of the signals start to decrease. Above $10 \mu \mathrm{M}$, the higher concentrations of salen ligands present at the surface of the nanoparticles can 15 cause over-aggregation of the colloid, or provide multilayer effects which will reduce the effective signal, while below $10 \mu \mathrm{M}$, there are too few ligand molecules on the surface which will also reduce the signal. As a result, a concentration of $10 \mu \mathrm{M}$ salen was used throughout this study as this concentration gave the strongest 20 SERS signals.
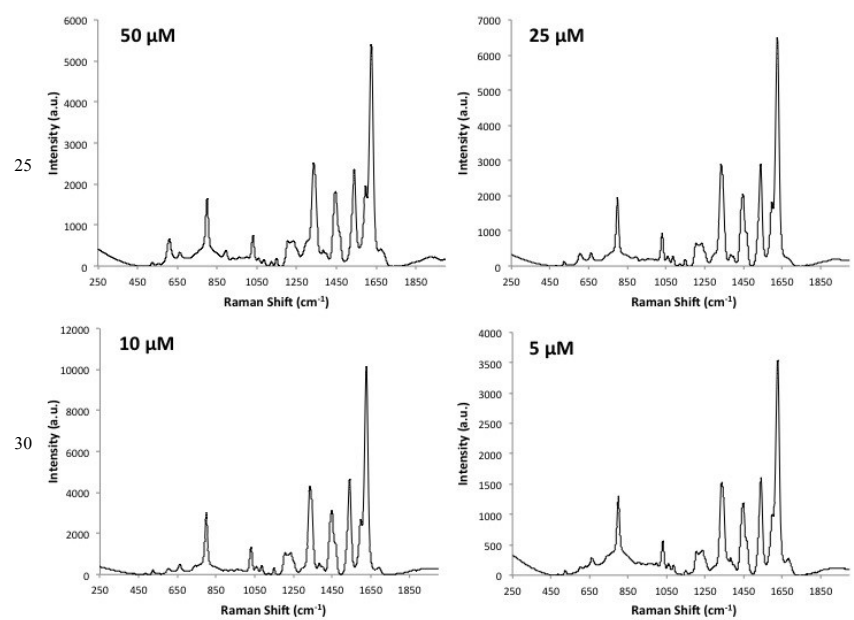

Figure 2: SERS spectra from different salen concentrations after addition of $1 \mu \mathrm{M} \mathrm{Ni}(\mathrm{II})$. Top left: $50 \mu \mathrm{M}$; top right: $25 \mu \mathrm{M}$; bottom left: $10 \mu \mathrm{M}$; bottom right: $5 \mu \mathrm{M}\left(\lambda_{\mathrm{ex}}=532 \mathrm{~nm}\right.$; acc. time $=10 \mathrm{~s}$ )

\section{Salen Complexes with Ni(II), Co(II), Cu(II) and Mn(II)}

35 To obtain the SERS spectra of the salen complexes, a $2.5 \mu \mathrm{M}$ solution of each metal salt was added to a solution of salen, followed by addition of AgNPs and aggregation with salt. The spectra acquired are compared in Figure 3, with the frequencies and assignments of the peaks listed in Table 1

40

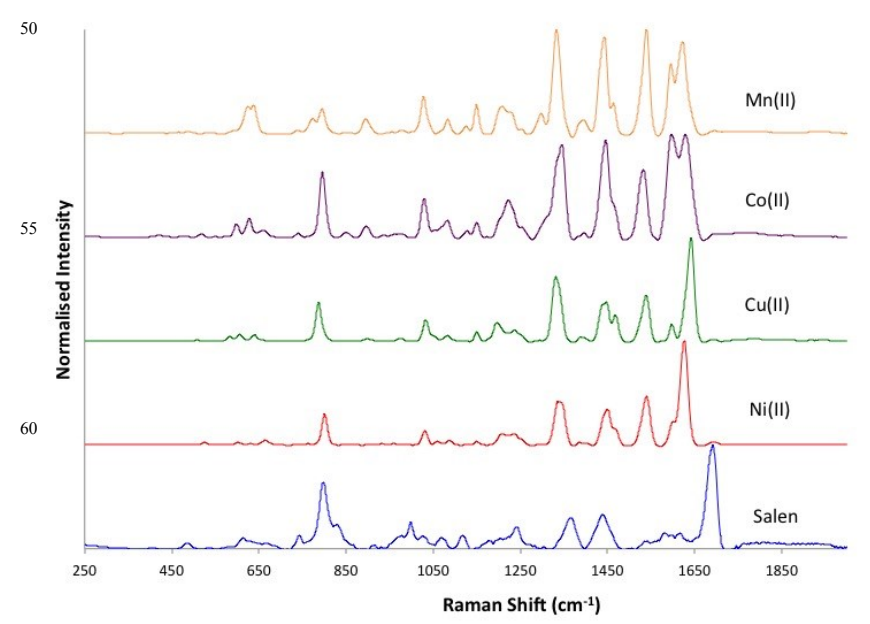

Figure 3: Comparison of the baseline corrected SERS spectra of the salen complexes studied, using $2.5 \mu \mathrm{M}$ solutions of each metal ion. Salen, blue; $\mathrm{Ni}(\mathrm{II})$, red; $\mathrm{Cu}(\mathrm{II})$, green; $\mathrm{Co}(\mathrm{II})$, purple; $\mathrm{Mn}(\mathrm{II})$, orange $\left(\lambda_{\mathrm{ex}}=532 \mathrm{~nm}\right.$; acc. time $\left.=10 \mathrm{~s}\right)$

Table 1: Frequencies and tentative assignments of the bands observed in the SERS spectra of the salen complexes ${ }^{23}$

\begin{tabular}{|c|c|c|c|c|c|}
\hline \multirow{15}{*}{$\begin{array}{l}\text { Frequenc } \\
\text { y }\left(\mathrm{cm}^{-1}\right)\end{array}$} & $\mathrm{Ni}(\mathrm{II})$ & $\mathrm{Co}(\mathrm{II})$ & $\mathrm{Cu}(\mathrm{II})$ & $\mathrm{Mn}(\mathrm{II})$ & Assignment \\
\hline & $\begin{array}{l}1627 . \\
5(s)\end{array}$ & $\begin{array}{l}1628 \\
\text { (s) }\end{array}$ & $\begin{array}{l}1641 . \\
5(\mathrm{~s})\end{array}$ & $\begin{array}{l}1621 . \\
5(\mathrm{~s})\end{array}$ & \multirow[t]{2}{*}{$\mathrm{C}=\mathrm{N} / \mathrm{C}=\mathrm{C}$} \\
\hline & $\begin{array}{l}1600 . \\
5 \text { (sh) }\end{array}$ & $\begin{array}{l}1597 \\
\text { (s) }\end{array}$ & $\begin{array}{l}1597 \\
(w)\end{array}$ & $\begin{array}{l}1597 \\
\text { (s) }\end{array}$ & \\
\hline & $\begin{array}{l}1541 \\
(\mathrm{~m})\end{array}$ & $\begin{array}{l}1531 \\
(\mathrm{~m})\end{array}$ & $\begin{array}{l}1538 \\
(\mathrm{~m})\end{array}$ & $\begin{array}{l}1538 \\
(\mathrm{~s})\end{array}$ & \multirow[t]{3}{*}{$\begin{array}{l}\text { Aromatic } \\
\text { ring stretch }\end{array}$} \\
\hline & & & $\begin{array}{l}1467 \\
(\mathrm{~m})\end{array}$ & $\begin{array}{l}1463 . \\
5(\mathrm{~m})\end{array}$ & \\
\hline & $\begin{array}{l}1449 \\
(\mathrm{~m})\end{array}$ & $\begin{array}{l}1445 . \\
5(s)\end{array}$ & $\begin{array}{l}1448 . \\
5(m)\end{array}$ & $\begin{array}{l}1441 . \\
5(\mathrm{~s})\end{array}$ & \\
\hline & & & $\begin{array}{l}1387 . \\
5(w)\end{array}$ & $\begin{array}{l}1394 . \\
5(w)\end{array}$ & $\begin{array}{l}\mathrm{N}-\mathrm{CH}_{2}- \\
\text { symmetric } \\
\text { deformatio } \\
\mathrm{n} \text { vibration }\end{array}$ \\
\hline & $\begin{array}{l}1335 . \\
5(\mathrm{~m})\end{array}$ & $\begin{array}{l}1346 . \\
5(s)\end{array}$ & $\begin{array}{l}1331 . \\
5(\mathrm{~m})\end{array}$ & $\begin{array}{l}1332 \\
\text { (s) }\end{array}$ & $\begin{array}{l}\mathrm{CH} \\
\text { deformatio } \\
\mathrm{n} \text { of alkyl } \\
\text { groups }\end{array}$ \\
\hline & & & & $\begin{array}{l}1298 \\
(w)\end{array}$ & \\
\hline & $\begin{array}{l}1237 . \\
5(w)\end{array}$ & $\begin{array}{l}1222 . \\
5(\mathrm{~m})\end{array}$ & $\begin{array}{l}1237 . \\
5(w)\end{array}$ & $\begin{array}{l}1226 . \\
5(\mathrm{~m})\end{array}$ & $\begin{array}{l}\mathrm{CH}_{2} \\
\text { wagging } \\
\text { vibration }\end{array}$ \\
\hline & $\begin{array}{l}1207 . \\
5(w)\end{array}$ & & $\begin{array}{l}1195 . \\
5(w)\end{array}$ & $\begin{array}{l}1207 \\
(\mathrm{~m})\end{array}$ & $\begin{array}{l}\mathrm{CH}_{2} \\
\text { twisting } \\
\text { vibration }\end{array}$ \\
\hline & $\begin{array}{l}1149 \\
(w)\end{array}$ & $\begin{array}{l}1149 \\
(w)\end{array}$ & $\begin{array}{l}1149 \\
(w)\end{array}$ & $\begin{array}{l}1149 \\
(\mathrm{~m})\end{array}$ & $\begin{array}{l}\text { C-C } \\
\text { stretching }\end{array}$ \\
\hline & & $\begin{array}{l}1129 . \\
5(w)\end{array}$ & & $\begin{array}{l}1125 . \\
5(w)\end{array}$ & \\
\hline & $\begin{array}{l}1086 . \\
5(w)\end{array}$ & $\begin{array}{l}1082 . \\
5(w)\end{array}$ & $\begin{array}{l}1082 . \\
5(w)\end{array}$ & $\begin{array}{l}1082 . \\
5(w)\end{array}$ & $\begin{array}{l}\text { C-C } \\
\text { stretching }\end{array}$ \\
\hline & 1058. & & & & Aromatic C- \\
\hline
\end{tabular}




\begin{tabular}{|c|c|c|c|c|}
\hline $5(w)$ & & & & $\begin{array}{l}\mathrm{H} \text { in-plane } \\
\text { deformatio } \\
\mathrm{n}\end{array}$ \\
\hline $\begin{array}{l}1030 . \\
5(w)\end{array}$ & $\begin{array}{l}1030 . \\
5(\mathrm{~m})\end{array}$ & $\begin{array}{l}1034 . \\
5(\mathrm{~m})\end{array}$ & $\begin{array}{l}1026 . \\
5(\mathrm{~m})\end{array}$ & $\begin{array}{l}\text { Ring } \\
\text { breathing }\end{array}$ \\
\hline & & & $\begin{array}{l}978 \\
(w)\end{array}$ & \\
\hline & $\begin{array}{l}896 \\
(w)\end{array}$ & & $\begin{array}{l}896 \\
(w)\end{array}$ & \\
\hline & $\begin{array}{l}850.5 \\
(w)\end{array}$ & & & \\
\hline $\begin{array}{l}800 \\
(\mathrm{~m})\end{array}$ & $\begin{array}{l}795.5 \\
\text { (m) }\end{array}$ & $\begin{array}{l}787.5 \\
(\mathrm{~m})\end{array}$ & $\begin{array}{l}795.5 \\
\text { (m) }\end{array}$ & $\begin{array}{l}\text { Aromatic C- } \\
\mathrm{H} \text { out-of- } \\
\text { plane } \\
\text { deformatio } \\
\mathrm{n}\end{array}$ \\
\hline & & & $\begin{array}{l}774.5 \\
\text { (w) }\end{array}$ & \\
\hline & $\begin{array}{l}740.5 \\
\text { (w) }\end{array}$ & & $\begin{array}{l}740.5 \\
\text { (w) }\end{array}$ & \\
\hline $\begin{array}{l}663 \\
(w)\end{array}$ & $\begin{array}{l}662 \\
(w)\end{array}$ & & & \\
\hline $\begin{array}{l}632 \\
(w)\end{array}$ & $\begin{array}{l}627.5 \\
(w)\end{array}$ & $\begin{array}{l}640.5 \\
(w)\end{array}$ & $\begin{array}{l}636.5 \\
(\mathrm{~m}) \\
\end{array}$ & \multirow{3}{*}{$\begin{array}{l}\text { Metal- } \\
\text { ligand } \\
\text { vibration }\end{array}$} \\
\hline $\begin{array}{l}601 \\
(w)\end{array}$ & $\begin{array}{l}597 \\
(w)\end{array}$ & $\begin{array}{l}605.5 \\
\text { (w) }\end{array}$ & & \\
\hline & & $\begin{array}{l}583.5 \\
\text { (w) }\end{array}$ & & \\
\hline
\end{tabular}

The spectra of the salen complexes demonstrate that coordination to different metal ions results in clear and distinct changes between each metal complex. Upon coordination to the various metal ions, 5 changes in intensity and frequency of a number of bands can be observed, which are likely to be dependent on the nature of the coordinating metal ion, e.g. size, mass, coordination bond strength. ${ }^{23}$ One of the main changes between each of the complexes involves the two bands around $1600 \mathrm{~cm}^{-1}$, which are attributed 10 mainly to the $\mathrm{C}=\mathrm{N}$ stretch of Schiff bases. ${ }^{23}$ For Ni(II), a strong band is observed at $1627 \mathrm{~cm}^{-1}$, with a shoulder at $1600 \mathrm{~cm}^{-1}$. However, for $\mathrm{Cu}(\mathrm{II})$, this band shifts to $1641 \mathrm{~cm}^{-1}$, with a weak band at $1597 \mathrm{~cm}^{-1}$. For $\mathrm{Co}(\mathrm{II})$ and $\mathrm{Mn}(\mathrm{II})$, these bands also vary significantly, with two strong bands at 1628 and $1597 \mathrm{~cm}^{-1}$ for ${ }_{15} \mathrm{Co}$ (II), and 1621 and $1597 \mathrm{~cm}^{-1}$ for $\mathrm{Mn}(\mathrm{II})$. These changes are likely due to the binding of the different metal ions to the nitrogen atoms of the ligand, causing the frequency of these bands to change. The strong differences in these peaks allow them to be used as marker bands for the identification and quantitation of the 20 four metal ions.

Numerous bands can be used to discriminate between the different complexes. For example, the frequencies of other stretches with a significant aromatic contribution also differ, improving the certainty with which the metal ions can be 25 identified. For $\mathrm{Ni}(\mathrm{II}), \mathrm{Cu}(\mathrm{II})$ and $\mathrm{Mn}(\mathrm{II})$, an aromatic stretch occurs $\sim 1538 \mathrm{~cm}-1$, however, a relatively large shift of around $7 \mathrm{~cm}^{-1}$ occurs for $\mathrm{Co}$ (II) and this can be used as a significant marker band for the presence of this metal ion. For the second aromatic stretch, each of the metal ions have a different frequency; 1449, 1467, 1445 30 and $1463 \mathrm{~cm}-1$ for $\mathrm{Ni}(\mathrm{II}), \mathrm{Cu}(\mathrm{II}), \mathrm{Co}(\mathrm{II})$ and $\mathrm{Mn}(\mathrm{II})$, respectively.
These changes in the aromatic stretches are likely due to the metal ions binding to the functional groups attached to the ring (the $\mathrm{O}$ and $\mathrm{N}$ atoms), resulting in changes to the electron density, and hence, polarisability of the ring groups.

35

\section{Principal Component Analysis (PCA)}

Although the metal ions can be clearly distinguished by examining the SERS spectra, principal component analysis (PCA) was used to extract the data and statistically highlight the differences 40 between the samples. PCA was carried out on 18 samples of each metal ion (three replicates of six different concentrations: 2.5, 2, $1.5,0.75,0.5$ and $0.25 \mu \mathrm{M})$. The scores plot for the four metal ions is shown in Figure 4.

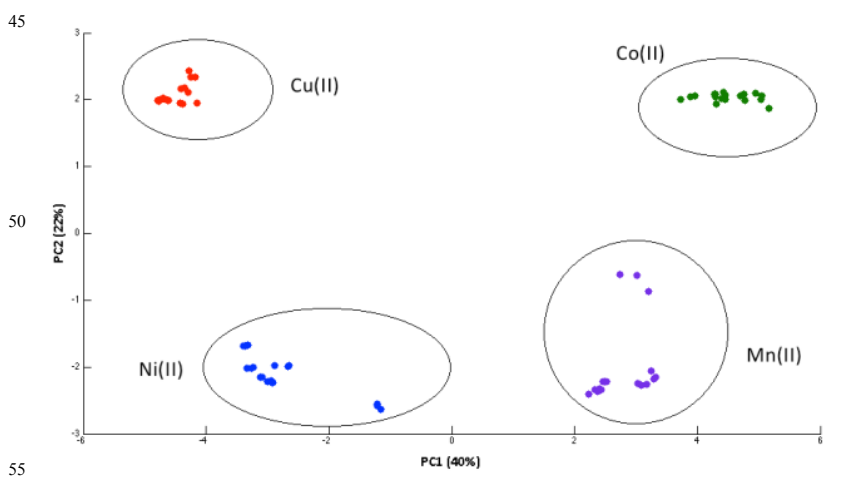

55 Figure 4: PCA scores plot of the different salen-metal ion complexes. Ni(II), blue; $\mathrm{Cu}(\mathrm{II})$, red; $\mathrm{Co}(\mathrm{II})$, green; $\mathrm{Mn}(\mathrm{II})$, purple

Each metal ion forms well-separated clusters, emphasising that each complex has different spectroscopic features that allow them 60 to be unambiguously identified. It also shows little variation between the different concentrations of the same metal ion, demonstrating the reproducibility of the spectra from the same complex when the concentration of the metal ion is varied.

\section{${ }_{65}$ Limit of Detection (LOD) Studies}

In order to determine if this method could be used to detect hazardous levels of these metal ions, LODs were calculated from the concentration dependent graphs shown in Figure 5.
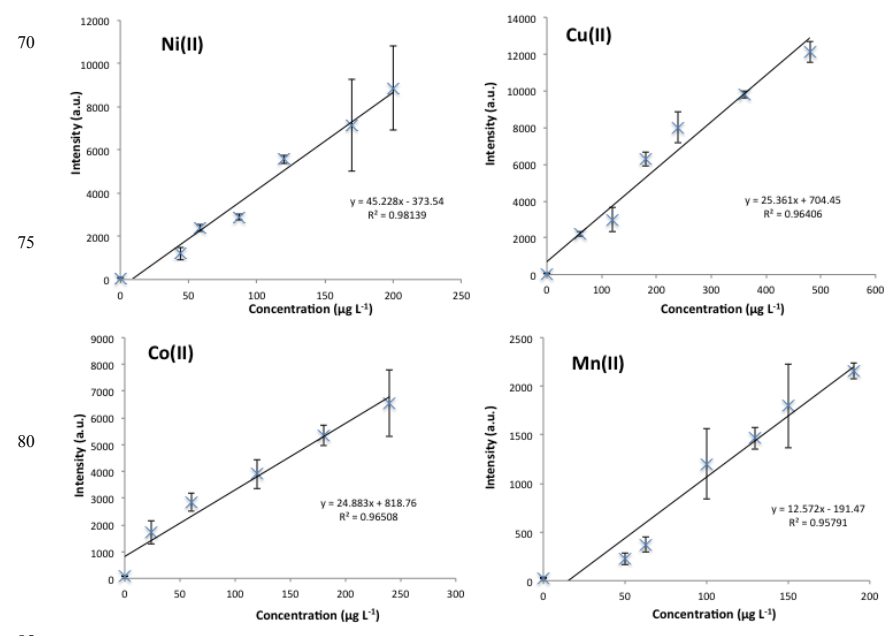
Figure 5: LOD graphs for each salen-metal complex. Top left: $\mathrm{Ni}(\mathrm{II})$ (I $\mathrm{I}_{1627}$ vs conc.); top right: $\mathrm{Cu}(\mathrm{II})$ (I $\mathrm{I}_{1638}$ vs conc.); bottom left: $\mathrm{Co}(\mathrm{II})$ (I1597 vs conc.); bottom right: $\mathrm{Mn}(\mathrm{II})$ (I 1332 vs conc.).

Error bars represent the standard deviation between the three replicates. $\left(\lambda_{\mathrm{ex}}=532 \mathrm{~nm}\right.$; acc. time $\left.=10 \mathrm{~s}\right)$

The graphs were constructed by taking the most intense and unique peak for each metal ion and plotting its intensity against concentration. The LODs, calculated by multiplying the standard deviation of the blank sample by 3 and dividing this by the gradient 10 of the line, are listed in Table 2 along with the recommended limits in drinking water as defined by the WHO. ${ }^{21}$ From Table 2, it is evident that $\mathrm{Ni}(\mathrm{II}), \mathrm{Cu}(\mathrm{II})$ and $\mathrm{Mn}(\mathrm{II})$ can be detected below the WHO's recommended limits at concentrations of $0.001,0.002$ and $0.002 \mathrm{mg} \mathrm{L}^{-1}$, respectively. $\mathrm{Co}(\mathrm{II})$ does not have a recommended

15 limit as it is rarely detected in drinking water, with concentrations usually ranging from $0.1-5 \mu \mathrm{g} \mathrm{L}^{-1}$, however $\mathrm{Co}$ (II) still poses a threat to the environment via other media such as soil. ${ }^{24}$

Table 2: Comparison of the detection limits obtained using 20 distilled water and freshwater. The recommended WHO limits in drinking water are also listed

\begin{tabular}{|c|c|c|c|}
\hline Metal Ion & $\begin{array}{c}\text { Detection } \\
\text { Limit } \\
(\mathbf{d . H} \mathbf{2} \text { ) } \\
\mathbf{m g ~ L}^{-1} \text { ) }\end{array}$ & $\begin{array}{c}\text { Detection } \\
\text { Limit (real } \\
\text { freshwater) } \\
\text { mg L }^{-1} \text { ) }\end{array}$ & $\begin{array}{c}\text { WHO } \\
\text { Guideline ( } \\
\left.\text { mg L }^{-1}\right)\end{array}$ \\
\hline $\mathrm{Co}(\mathrm{II})$ & $0.02 \pm 0.01$ & $0.12 \pm 0.5$ & - \\
\hline $\mathrm{Cu}(\mathrm{II})$ & $0.002 \pm 0.02$ & $0.48 \pm 1.8$ & 2 \\
\hline $\mathrm{Mn}(\mathrm{II})$ & $0.002 \pm 0.03$ & $0.63 \pm 1.8$ & 0.5 \\
\hline $\mathrm{Ni}(\mathrm{II})$ & $\begin{array}{c}0.001 \pm \\
0.009\end{array}$ & $0.73 \pm 2.7$ & 0.02 \\
\hline
\end{tabular}

\section{Real Freshwater Samples}

These results demonstrate the ability of this method to detect four 25 metal ions using SERS. However these tests were done using distilled water whereas the composition of environmental samples are more complex, and may contain matrix species that interfere with the detection of the metal ions. Therefore, freshwater was collected from Loch Thom, Greenock in order to test this method 30 with real environmental samples.

Firstly, the composition of the freshwater was obtained using ICP-MS analysis, where the concentration of $\mathrm{Ni}$ (II), $\mathrm{Cu}$ (II), $\mathrm{Co}$ (II) and $\mathrm{Mn}(\mathrm{II})$ present was $0.9 \pm 0.001,3.7 \pm 1.6,0.1 \pm 0.01$ and $17.3 \pm 0.08 \mu \mathrm{g} \mathrm{L}^{-1}$, respectively $(\mathrm{n}=3)$. The freshwater after addition 35 of salen, was then analysed using SERS. However, a large signal was observed which is believed to be from organic material, as the spectrum did not match those from the metal ions of interest, and the concentrations of metal ions in the water sample were not sufficient to cause such a strong signal.

40 As $\mathrm{Ni}(\mathrm{II}), \mathrm{Cu}(\mathrm{II}), \mathrm{Co}(\mathrm{II})$ and $\mathrm{Mn}(\mathrm{II})$ were not present in the sample at high levels, the freshwater was spiked with varying concentrations of these ions and the SERS spectra acquired. However at lower metal ion concentrations, the SERS spectrum of the interferent dominated, masking features that are specific to

45 each metal ion of interest. The freshwater standard also produced a strong SERS signal and therefore, concentration relationships were plotted as shown in Figure 6. Observable detection limits were subsequently obtained (stated in Table 2) by using the lowest metal ion concentration that clearly produced the characteristic ${ }_{50}$ SERS spectrum that is associated with each metal-salen complex. Below this concentration, the SERS spectrum of the interferent dominated and therefore $\mathrm{Ni}(\mathrm{II}), \mathrm{Cu}(\mathrm{II}), \mathrm{Mn}$ (II) or $\mathrm{Co}(\mathrm{II})$ could not be confidently identified. Due to this interferent, the detection limits for the real freshwater samples were higher than those of the 55 distilled water, as can be seen in Table 2. Although the detection limits are higher, this method was able to prove that the metal ions were not present in the freshwater at levels likely to have a negative impact on human or environmental health.
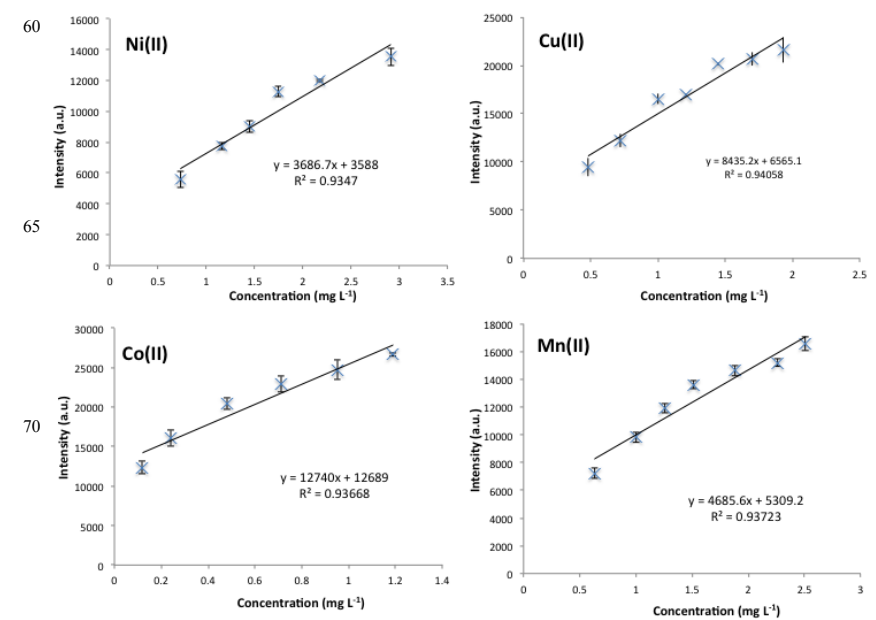

Figure 6: Concentration dependence of each salen-metal complex in real freshwater. Top left: $\mathrm{Ni}(\mathrm{II})\left(\mathrm{I}_{1627}\right.$ vs. conc.); top right: $\mathrm{Cu}$ (II) (I $\mathrm{I}_{1638}$ vs. conc.); bottom left: $\mathrm{Co}$ (II) (I 1597 vs. conc.); bottom right: $\mathrm{Mn}(\mathrm{II})$ (I $\mathrm{I}_{1332}$ vs. conc.). Error bars represent the standard deviation between three replicates. $\left(\lambda_{\mathrm{ex}}=532 \mathrm{~nm}\right.$, acc. time $=10 \mathrm{~s}$ )

75

\section{Contaminated Water}

After testing the SERS sensor with natural freshwater, contaminated water was obtained from Gourock burn which is known to have leachate issues due to a nearby landfill site. The 80 SERS spectrum obtained from this water sample was almost identical to that of the $\mathrm{Mn}$ (II)-salen complex in distilled water, and these are compared in Figure 7. The slight differences around 1450 $\mathrm{cm}^{-1}$ and $1275 \mathrm{~cm}^{-1}$ are attributed to the different sample matrices.

85

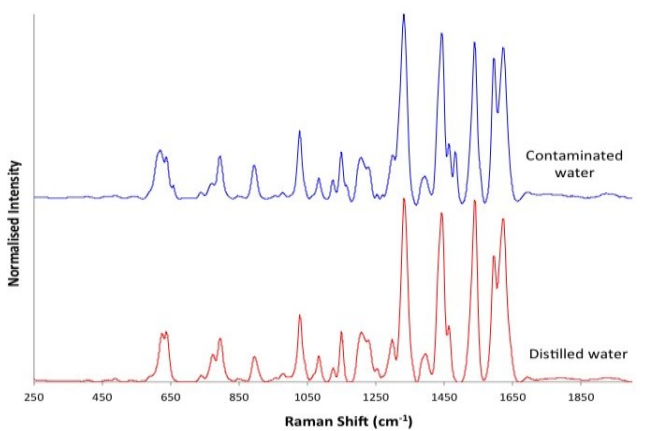


Figure 7: Comparison of Mn(II)-salen SERS spectrum from contaminated water (top) to the $\mathrm{Mn}(\mathrm{II})$-salen SERS spectrum in distilled water (bottom). $\left(\lambda_{\mathrm{ex}}=532 \mathrm{~nm}\right.$, acc. time $\left.=10 \mathrm{~s}\right)$

In order to confirm that $\mathrm{Mn}$ (II) was present in the water sample, ICP-MS analysis was conducted and this showed that Mn(II) was indeed present at a concentration of $833 \pm 37 \mu \mathrm{g} \mathrm{L}^{-1}(\mathrm{n}=3)$ (the 10 concentrations of $\mathrm{Ni}(\mathrm{II}), \mathrm{Co}$ (II) and $\mathrm{Cu}$ (II) were $1.7 \pm 0,04$, $0.6 \pm 0.02$ and $1.9 \pm 0.07 \mu \mathrm{g} \mathrm{L^{-1 }}$, respectively). The SERS analysis indicated that a $\mathrm{Mn}(\mathrm{II})$ concentration of approximately $700 \mu \mathrm{g} \mathrm{L}^{-1}$ was present, as the intensity of the $1332 \mathrm{~cm}^{-1}$ stretch (i.e. the band used to plot the concentration relationships in Figure 6) occurred 15 at $\sim 7000$ counts, as shown in the SI which displays the SERS spectrum obtained from the contaminated freshwater sample. This is reasonably similar to the results of the ICP-MS analysis indicating that this method is capable of detecting high levels of metal ions in contaminated water samples.

\section{${ }_{20}$ Conclusions}

It has been demonstrated that a nanoparticle-based sensor has been developed, capable of detecting $\mathrm{Ni}$ (II), $\mathrm{Cu}$ (II), $\mathrm{Co}$ (II) and $\mathrm{Mn}$ (II) using SERS. The coordination of each of these metal ions to salen visibly changes the SERS spectrum of this ligand, and the changes 25 produced are specific to each ion. As a result, this allows clear discrimination between each of the analytes. LOD experiments demonstrated that $\mathrm{Ni}(\mathrm{II}), \mathrm{Cu}$ (II) and $\mathrm{Mn}$ (II) could be detected below the recommended WHO level in drinking water. However these LODs were obtained using distilled water and therefore, the 30 method was tested using real environmental samples; one freshwater sample with low concentrations of the metal ions of interest, and one contaminated water sample with a high concentration of $\mathrm{Mn}$ (II). The uncontaminated water contained an interferent, believed to be organic material, which affected the 35 detection at low concentrations. Nonetheless, it still proved that the metal ions were not present at levels that could be deemed harmful to the environment. The SERS spectrum obtained from the contaminated water showed the presence of Mn(II) and ICP-MS confirmed that this ion was present at a concentration of $833 \mu \mathrm{g} \mathrm{L}$ $40{ }^{1}$. Therefore, it has been shown that this SERS method for detecting metal ions can be used for the sampling of real environmental samples. ICP-MS is clearly a superior method as it can detect $>50$ elements at ng/L levels within a couple of minutes. ${ }^{25}$ However, the SERS method described is a much cheaper and simpler alternative 45 that can detect the metal ions of interest at $\mu \mathrm{g} / \mathrm{L}$ levels and using an analysis time of $5 \mathrm{~s}$.

Compared to our previous work using 2,2'-bipyridyl, although a smaller range of metal ions were studied, the sensitivity is improved using salen. The method has also been tested with real 50 environmental water samples and was able to detect the presence of $\mathrm{Mn}(\mathrm{II})$ in a contaminated water sample. In regards to similar published work, the detection limits for this research are generally higher, e.g. the cyanide system described by Kim et al. quote LODs at the $\mathrm{fM}$ level while Tsoutsi et al. can detect $\mathrm{Cu}$ (II) and $\mathrm{Co}$ (II) at ${ }_{55}$ levels of $6.5 \mu \mathrm{g} \mathrm{L}^{-1}$ and $60 \mathrm{ng} \mathrm{L}^{-1}$, respectively. ${ }^{18,19}$ Nevertheless, the detection limits using salen fall below the recommended WHO levels in drinking water and we have also tested our method with natural environmental freshwater in order to ensure that it can be applied to more realistic water samples. Our method also exhibits ${ }_{60}$ distinct changes throughout the spectral range which confers greater confidence in the discrimination of the different metal ions. As a result, we have demonstrated the potential of SERS to be used as a low-cost environmental monitoring technique for metal ions.

\section{Acknowledgement}

${ }_{65}$ This work was supported by the Royal Society of Chemistry's Analytical Chemistry Trust Fund and the Natural Environment Research Council (NERC) [NE/J01771X/1]. DG thanks the Royal Society for support from a Wolfson Research Merit Award. The research data associated with this paper has the following DOI: 70 10.15129/38671508-b630-4276-820c-2fc6bdbe6fae The authors would like to thank Roslyn McIntosh at Inverclyde council for recommending and allowing access to sampling sites.

\section{Notes and references}

${ }^{a}$ Centre for Molecular Nanometrology, WestCHEM, Pure \& Applied

75 Chemistry, University of Strathclyde, 99 George St., Glasgow, G1 IRD,

UK.E-mail: duncan.graham@strath.ac.uk

${ }^{b}$ WestCHEM, Pure \& Applied Chemistry, University of Strathclyde, 295 Cathedral Street, Glasgow, G1 1XL, UK.

$\uparrow$ Electronic Supplementary Information (ESI) available: [details of any 80 supplementary information available should be included here]. See DOI: $10.1039 / \mathrm{b} 000000 \mathrm{x} /$

\begin{tabular}{|c|c|}
\hline 1. & H. Schiff, Justus Liebigs Annalen der Chemie, 1864, 131, 118 \\
\hline 85 & 119. \\
\hline 2. & P. G. Cozzi, Chemical Society Reviews, 2004, 33, 410-421. \\
\hline 3. & $\begin{array}{l}\text { A. Prakash and D. Adhikari, International Journal of Che } \\
\text { Tech Research, 2011, 3, 1891-1896. }\end{array}$ \\
\hline 4. & P. G. Cozzi, Chemical Society Reviews, 2004, 33, 410-421. \\
\hline 905. & $\begin{array}{l}\text { K. C. Gupta and A. K. Sutar, Coordination Chemistry Reviews, } \\
\text { 2008, 252, 1420-1450. }\end{array}$ \\
\hline 6. & $\begin{array}{l}\text { A. Jarrahpour, D. Khalili, E. De Clercq, C. Salmi and J. M } \\
\text { Brunel, Molecules, 2007, 12, 1720-1730. }\end{array}$ \\
\hline 7. & C. M. da Silva, D. L. da Silva, L. V. Modolo, R. B. Alves, \\
\hline 95 & $\begin{array}{l}\text { A. de Resende, C. V. B. Martins and Â. de Fátima, Journal } \\
\text { Advanced research, 2011, 2, 1-8. }\end{array}$ \\
\hline 8. & $\begin{array}{l}\text { Z. L. You and H. L. Zhu, Zeitschrift für anorganische ur } \\
\text { allgemeine Chemie, 2004, 630, 2754-2760. }\end{array}$ \\
\hline 9. & T. Jeewoth, M. G. Bhowon and H. L. K. Wah, Transition Me \\
\hline 00 & Chemistry, 1999, 24, 445-448. \\
\hline 10. & $\begin{array}{l}\text { N. Dharmaraj, P. Viswanathamurthi and K. Natarajan } \\
\text { Transition Metal Chemistry, 2001, 26, 105-109. }\end{array}$ \\
\hline 11. & $\begin{array}{l}\text { V. K. Gupta, A. K. Singh, M. R. Ganjali, P. Norouzi, F. } \\
\text { Faridbod and N. Mergu, Sensors and Actuators B: Chemical, }\end{array}$ \\
\hline 05 & $2013, \mathbf{1 8 2}, 642-651$ \\
\hline 12. & $\begin{array}{l}\text { L. Wang, D. Ye and D. Cao, Spectrochimica Acta Part A } \\
\text { Molecular and Biomolecular Spectroscopy, 2012, 90, 40-44. }\end{array}$ \\
\hline 13. & $\begin{array}{l}\text { W. H. Hsieh, C.-F. Wan, D.-J. Liao and A.-T. Wu, Tetrahedror } \\
\text { Letters, 2012, 53, 5848-5851. }\end{array}$ \\
\hline 1014. & $\begin{array}{l}\text { L. Wang, W. Qin and W. Liu, Inorganic Chemis } \\
\text { Communications, 2010, 13, 1122-1125. }\end{array}$ \\
\hline 15. & $\begin{array}{l}\text { M. Hosseini, Z. Vaezi, M. R. Ganjali, F. Faridbod, S. D } \\
\text { Abkenar, K. Alizadeh and M. Salavati-Niasari, Spectrochimic } \\
\text { Acta Part A: Molecular and Biomolecular Spectroscopy, } 201\end{array}$ \\
\hline 15 & $\mathbf{7 5}, 978-982$ \\
\hline 16. & $\begin{array}{l}\text { L. Tang, F. Li, M. Liu and R. Nandhakumar, Spectrochimi } \\
\text { Acta Part A: Molecular and Biomolecular Spectroscopy, } 201 \\
\text { 78, 1168-1172. }\end{array}$ \\
\hline 17. & $\begin{array}{l}\text { Y. W. Choi, G. J. Park, Y. J. Na, H. Y. Jo, S. A. Lee, G. R. Y } \\
\text { and C. Kim, Sensors and Actuators B: Chemical, 2014, } 19 \\
\text { 343-352. }\end{array}$ \\
\hline
\end{tabular}


18. K. Kim, J. W. Lee and K. S. Shin, Analyst, 2013, 138, 29882994.

19. D. Tsoutsi, L. Guerrini, J. M. Hermida-Ramon, V. Giannini, L. M. Liz-Marzan, A. Wei and R. A. Alvarez-Puebla, Nanoscale,

$52013, \mathbf{5}, 5841-5846$.
J. Docherty, S. Mabbott, W. E. Smith, J. Reglinski, K. Faulds,

C. Davidson and D. Graham, Analyst, 2015, 140, 6538-6543.

21. WHO, WHO Guidelines for drinking-water quality, World Health Organization, Geneva, 2011.

$1022 . \quad$ P. C. Lee and D. Meisel, The Journal of Physical Chemistry, 1982, 86, 3391-3395.

23. G. Socrates, Infrared and Raman Characteristic Group Frequencies: Tables and Charts, Wiley, 2004.

24. WHO, Cobalt and Inorganic Cobalt Compounds, World Health $15 \quad$ Organization, Geneva, 2006.

25. H. B. Bradl, Heavy Metals in the Environment, Elsevier Academic Press, 2005. 


\section{Detection of Potentially Toxic Metals by SERS using Salen Complexes}

Julie Docherty, Samuel Mabbott, Ewen Smith, Karen Faulds, Christine Davidson, John Reglinski and Duncan Graham

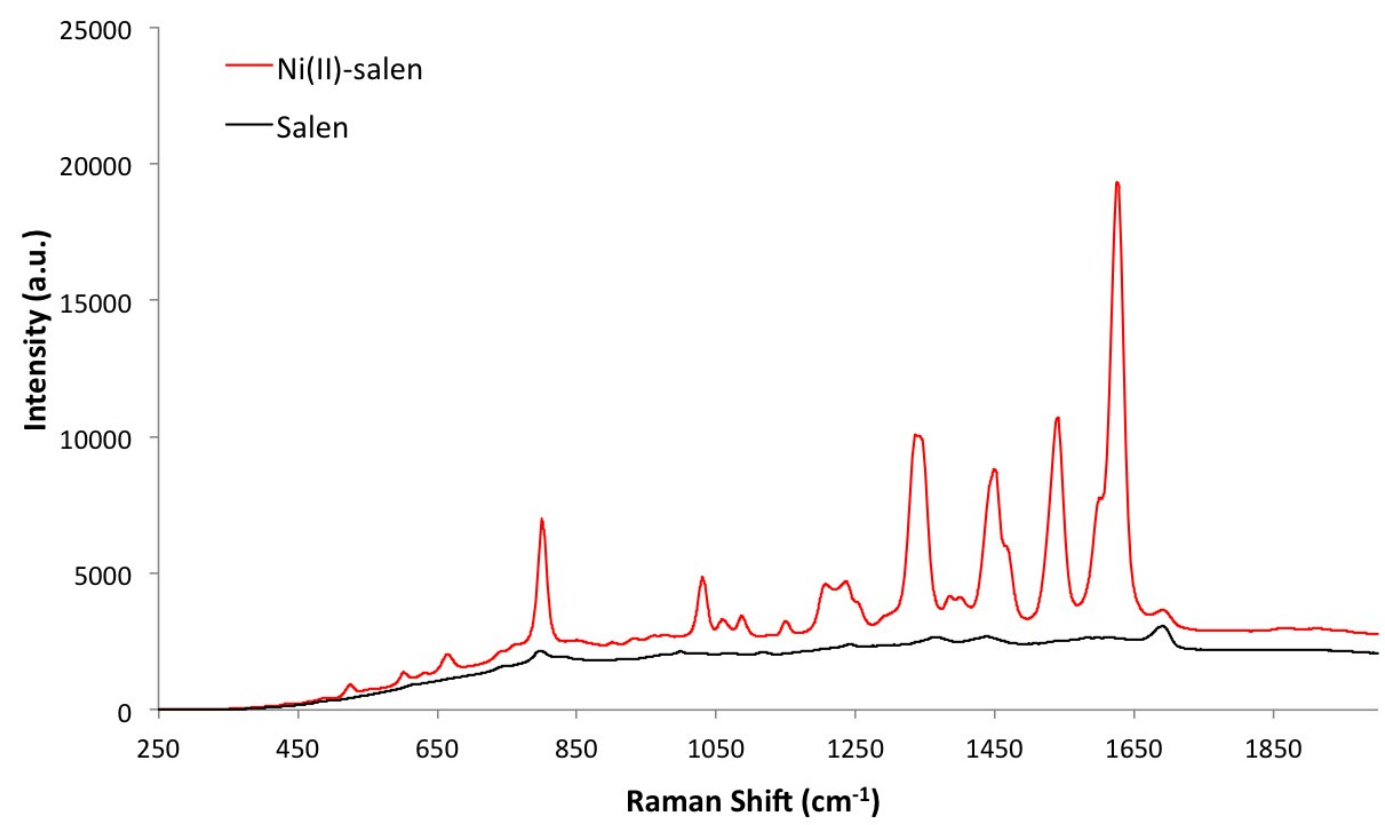

Figure S 1: Comparison of the SERS spectrum of the free salen ligand (black) to that of the Ni(II)-salen complex (red) $\left(\lambda_{\text {ex }}=532 \mathrm{~nm}\right.$; acc. time $\left.=10 \mathrm{~s}\right)$

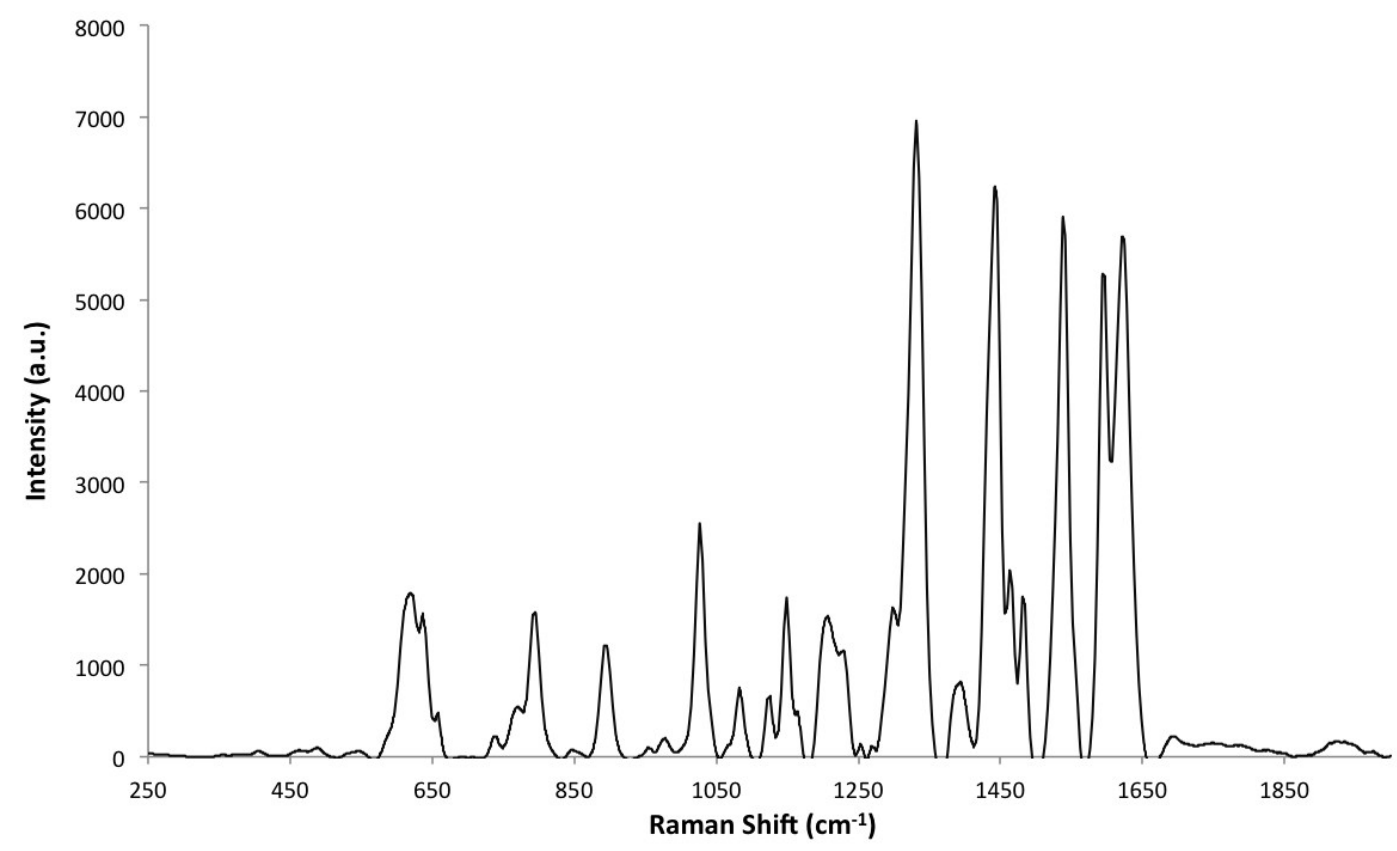

Figure S 2: SERS spectrum obtained from the contaminated freshwater $\left(\lambda_{\mathrm{ex}}=532 \mathrm{~nm}\right.$; acc. time $\left.=10 \mathrm{~s}\right)$ 